\title{
Use of combined oral contraceptive pills among teenage girls in Calabar, Nigeria
}

This article was published in the following Dove Press journal:

Open Access Journal of Contraception

23 July 2012

Number of times this article has been viewed

\author{
Christopher U Iklaki' \\ John E Inaku \\ John E Ekabua' \\ Patience O Odusolu' \\ Charles O Njoku' \\ 'Department of Obstetrics and \\ Gynaecology, University of Calabar, \\ Calabar, Nigeria; ${ }^{2}$ Department \\ of Obstetrics and Gynaecology, \\ University of Calabar Teaching \\ Hospital, Calabar, Nigeria
}

\begin{abstract}
The objective of this study was to find out about the use of combined oral contraceptive pills by women in Calabar, Nigeria, with a particular interest in single nulliparous teenage women. During the period from 2006 to 2010, a total of 1980 women seen in the University of Calabar Teaching Hospital's family planning unit used various methods of contraception. Of these, 316 (15.96\%) used combined oral contraceptive pills. Twenty girls aged between 13 and 19 years accounted for $6.3 \%$ of those who used combined oral contraceptive pills. There were $296(93.6 \%)$ women between the ages of 20 and 34 years who accounted for the remaining users. Of these women, 195 (61.5\%) were educated to the secondary level, and 34 (10.8\%) were educated to primary level. No women without formal education used combined oral contraceptive pills during the period of study. The majority of the users were nulliparous $(128 ; 40.4 \%)$; the rest had parity values of at least one to more than four. One hundred thirty-seven (43.4\%) of the users were single, 112 (35.4\%) were married, and the remaining 67 (21.1\%) were separated, divorced, or widowed. There is a growing need to educate young Nigerian women about the use of combined oral contraceptive pills; this medication is suitable and effective for most young women, and it also has additional noncontraceptive health benefits.
\end{abstract}

Keywords: combined, oral, contraception, pills

Contraception is the use of various devices, drugs, agents, sexual practices, or surgical procedures to prevent conception. ${ }^{1}$ It is used for birth control, the spacing of pregnancies, and the limitation of family size. ${ }^{1-3}$ Contraception has been a very sensitive and controversial subject in traditional African society as a result of the society's inherent barriers to the use of contraception. ${ }^{4,5}$ These barriers include a lack of awareness, a lack of access, cultural factors, religion, an opposition to the use of contraception by sexual partners or family members, and a fear of the health risks and side effects associated with contraceptives. ${ }^{6,7}$ In Nigeria, for example, the attitude of the government toward contraception has changed from lukewarm to rather positive; this resulted in the inclusion of family planning as an integral component of the primary health care delivery system in $1988 .{ }^{8}$ This development has led to an increased awareness and use of various methods of contraception by women in this country.

There are various methods of contraception, including progesterone-only implants, injectable progesterone-only methods, intrauterine contraceptive devices, barrier methods, spermicides, surgical sterilization, oral progesterone-only pills, and combined oral contraceptive pills..$^{9-11}$ Combined contraceptive pills first became available during the 1960s. ${ }^{9}$ Since that time, these pills have remained the most common method of contraception used by women aged between 15 and 34 years, especially in the developed
Correspondence: John E Ekabua GPO Box 2522, Calabar Road, Calabar, Nigeria

Email johnekabua@yahoo.com 
countries of Europe and America. ${ }^{12-14}$ The combined oral contraceptive pill is essentially made up of an estrogen and a progesterone.

The two most common estrogens that are used in combined oral contraceptive pills are the synthetic products ethinyloestradiol and mestranol. ${ }^{15,16}$ These two estrogens are potent and active when they are taken orally. ${ }^{17,18}$ Scientists have continued to reduce the dose of estrogen in combined oral contraceptive pills; thromboembolism, which is a known complication of combined oral contraceptive pill use, results from the effects of the pill's estrogen component. ${ }^{19,20}$ Thus, there are three categories of combined oral contraceptive pills, which are based on estrogen content: low dose (containing $<50 \mu \mathrm{g}$ of estrogen); medium dose (containing $50 \mu \mathrm{g}$ of estrogen); and high dose (containing $>50 \mu \mathrm{g}$ of estrogen). ${ }^{9,21,22}$ The reduction in the estrogen component of combined oral contraceptive pills has not been found to decrease the efficacy of the pill..$^{9}$ The progesterone component is usually supplied by norethindrone, levonorgestrel, norgestrel, norethindrone acetate, or ethynodiol diacetate. Newer progesterones that are less androgenic have also been introduced; these include norgestimate, desogestrel, and gestodene. ${ }^{15,16,23}$ Combined oral contraceptive pills are packaged as monophasic or phasic oral contraceptives. ${ }^{9,21}$

The combined oral contraceptive pill is very effective, although efficacy depends on compliance with the treatment regimen. ${ }^{24,25}$ It is essential for the user to be well motivated and to remember to take the pill every day. Failure rate ranges from less than 1 per 100 women-years to more than 15 per 100 women-years. ${ }^{24}$ Again, this rate depends on user compliance. ${ }^{24,26}$ The pills are affordable, with a short recovery interval, and inadvertent use during early pregnancy is not known to be teratogenic. ${ }^{27}$ Long-term use is associated with improved iron reserves, minimal menstrual blood loss, and regular and predictable menstrual cycles. ${ }^{2,11,12}$

Combined oral contraceptive pill use is also associated with the relief of dysmenorrhea, the correction of dysfunctional uterine bleeding, and the amelioration of the course of rheumatoid arthritis. ${ }^{11,12,28}$ It is also known to protect women from pelvic inflammatory disease, ectopic pregnancies, and endometriosis. Long-term use helps to prevent the development of epithelial ovarian and endometrial carcinoma. The pills also protect users from benign breast diseases like fibroadenoma and fibrocystic breast disease. ${ }^{22,29}$ However, there is a small risk of hepatic adenoma among long-term users, a slight risk of breast carcinoma among predisposed women who are also taking the pill, and perhaps a small risk of squamous carcinoma of the cervix among long-term users. ${ }^{29}$
Combined oral contraceptive pills are contraindicated for pregnant women, women who smoke, and women who are 35 years old or older. The use of these pills is also contraindicated for women with previous thromboembolism, cardiovascular disease, or chronic liver disease. Most side effects of the pills are self-limiting. Treatment is often better tolerated if proper counseling precedes the commencement of the pills. ${ }^{17,30}$

The level of use of contraception among sexually active women in developing countries is generally low, especially in Africa. This is due to a prevailing lack of information as well as cultural and religious barriers. ${ }^{31-33}$ Several studies in different parts of Nigeria have shown a very low utilization rate that ranges from $5.3 \%$ to $20 \%{ }^{34,35}$ However, from 1990 to 2008 , Nigeria's national contraceptive prevalence rate increased from $6.0 \%$ to $14.6 \%{ }^{36}$ The Nigerian demographic health survey of 2008 showed that the median age at first sexual intercourse was 17.8 years for women between the ages of 20 and 49 years. ${ }^{36}$ In addition, although $28 \%$ of women between the ages of 45 and 49 years had their first instance of sexual intercourse by the age of 15 years, only $15 \%$ of women who are currently 15 to 19 years old have experienced the same. ${ }^{36}$ The problems that result from a low level of contraception use and increased sexuality are both numerous and formidable. ${ }^{37}$

The objective of this study was to determine the level of use of combined contraceptive pills among young teenage sexually active women in Nigeria.

\section{Materials and methods}

The setting of the study is Calabar, Nigeria, which is the capital of Cross River State. Calabar has an estimated population of 371,022, with women accounting for 184,415 (49.7\%) of the population. The area hosts one teaching hospital, a general hospital, and numerous private clinics. The records of clients who used various methods of contraception during the study period of January 1, 2006, to December 31, 2010 , at the family planning unit of the maternity annex of the University of Calabar Teaching Hospital were reviewed. During this period, 1980 women used various methods of contraception, and 316 (15.9\%) of these women used combined oral contraceptive pills. The records of clients who used these pills were selected for in-depth study. The research protocol fulfilled the criteria for approval by the research ethics committee. The demographic data and the contraceptive use of these women were analyzed with the use of the Epi Info statistical software package (version 3.5.1; Centers for Disease Control and Prevention, Atlanta, GA). 
The parameters used for the analysis were the proportion of teenagers who used combined oral contraceptive pills per year, the age group of the users, the educational status of the users, and the parity and marital status of the users. The results obtained are displayed in Tables 1-5.

Table I Yearly distribution of combined oral contraceptive pill use per year and teenage usage

\begin{tabular}{llcc}
\hline Years & $\begin{array}{l}\text { No. of } \\
\text { teenagers }\end{array}$ & $\begin{array}{l}\text { Total no. of } \\
\text { users }\end{array}$ & $\begin{array}{l}\text { Percentage per year } \\
\text { of teenagers }\end{array}$ \\
\hline 2006 & 2 & 56 & 3.6 \\
2007 & 5 & 60 & 8.3 \\
2008 & 4 & 86 & 4.6 \\
2009 & 3 & 64 & 4.7 \\
2010 & 6 & 50 & 12.0 \\
\hline Total & 20 & 316 & 6.4 \\
\hline
\end{tabular}

Table 2 Age distribution of users of combined oral contraceptive pills

\begin{tabular}{lcc}
\hline Age group (years) & No. of users & Percentage (\%) \\
\hline$<15$ & 4 & 1.3 \\
16 to 17 & 6 & 1.9 \\
18 to 19 & 10 & 3.2 \\
20 to 34 & 296 & 93.6 \\
\hline Total & 316 & 100 \\
\hline
\end{tabular}

Table 3 Educational status of users of combined oral contraceptive pills

\begin{tabular}{lcc}
\hline Level of education & No. of users & Percentage (\%) \\
\hline No formal education & 0 & 0.0 \\
Primary education & 34 & 10.8 \\
Secondary education & 195 & 61.5 \\
Tertiary education & 87 & 27.7 \\
\hline Total & 316 & 100 \\
\hline
\end{tabular}

Table 4 Parity of users of combined oral contraceptive pills

\begin{tabular}{lcc}
\hline Parity & No. of users & Percentage (\%) \\
\hline 0 & 128 & 40.4 \\
1 & 74 & 23.5 \\
2 & 54 & 17.0 \\
3 & 32 & 10.3 \\
$>4$ & 28 & 8.8 \\
\hline Total & 316 & 100 \\
\hline
\end{tabular}

Table 5 Marital status of users of combined oral contraceptive pills

\begin{tabular}{lcc}
\hline Marital status & No. of users & Percentage (\%) \\
\hline Single & 137 & 43.4 \\
Married & 112 & 35.4 \\
Separated & 23 & 7.3 \\
Divorced & 17 & 5.4 \\
Widowed & 27 & 8.5 \\
\hline Total & 316 & 100 \\
\hline
\end{tabular}

\section{Results}

During the period of study at the Family Planning Unit of the Maternity Annex of the University of Calabar Teaching Hospital, Calabar, the 1980 women studied used various methods of contraception, which included Norplant, Implanon, injectable progesterone-only methods, intrauterine contraceptive devices, condoms, bilateral tubal ligation, and combined oral contraceptive pill. Norplant consists of six flexible, silastic, nonbiodegradable subdermal implants, each containing $36 \mathrm{mg}$ levonorgestrel with an efficacy of 5 years. It was developed by the Population Council, Inc (New York, NY) and first used in Finland. Implanon (Merck \& Co., Inc, Whitehouse Station, NJ) is a single, nonbiodegradable subdermal implant containing $68 \mathrm{mg}$ of etonogestrel with an efficacy of 3 years. Three hundred sixteen $(15.9 \%)$ of these women used the combined oral contraceptive pill, and teenagers accounted for 20 (6.4\%) of those women who used combined oral conceptive pills. Women aged between 20 and 34 years accounted for 296 (93.6\%) of users. Eighty-seven (27.7\%) users were educated to the tertiary level, 195 (61.5\%) were educated to the secondary level, and $34(10.8 \%)$ were educated to the primary level. A total of 128 (40.4\%) users of combined oral contraceptive pill were nulliparous, whereas the remaining $59.6 \%$ had a parity value that ranged from one to more than four. One hundred thirty-seven (43.4\%) of the users were single, 112 (35.4\%) were married, and the remaining 67 (21.3\%) were separated, divorced, or widowed. See Tables 1 through 5 for a more detailed breakdown of this information.

\section{Discussion}

The University of Calabar Teaching Hospital is the foremost center for contraceptive counseling and service provision in Cross River State, Nigeria. This study has shown that the use of contraception by women in this community is low. An average of only about 396 women used contraceptive each year during the period under review. However, the low utilization rate is consistent with that of other studies performed in various parts of Nigeria, which showed a utilization rate of between $5.3 \%$ and $20 \% .^{34,35}$ This is even more understandable when one considers the national contraceptive prevalence rate of $14.6 \%$ in $2008 .^{36}$

This picture is in contrast with the rate of contraception use in the developed countries of Europe and America, where more than $90 \%$ of women who wish to avoid pregnancy have used a method of contraception. ${ }^{34}$ The majority of the women in this study who used contraception during the period under review were less than 35 years old, and only $15.9 \%$ of them used combined oral contraceptive pills. Perhaps this trend is 
also being seen in other health care centers in Nigeria. In the United Kingdom, combined oral contraceptive pills are the most common method of contraception, with condoms being a close second. ${ }^{11}$ Various studies in the six geopolitical zones of Nigeria have indicated that the main sources of contraceptives, in decreasing order of frequency, are patent medicine stores; pharmacy shops; friends, siblings, or partners; and health facilities. ${ }^{31-33}$ The low level of use of combined oral contraceptive pills by young women in this country is probably the result of a low level of awareness, misconceptions about the pill, and a lack of adolescent-friendly reproductive health services. ${ }^{7}$

Oral contraceptive pills - like condoms - are readily available over the counter at patent medicine stores and pharmacy shops in Nigeria; they are also available at health care facilities. These pills are the second contraceptive method of choice for women of reproductive age, particularly for younger unmarried females and students. ${ }^{36}$ A significant problem in Nigeria is a general lack of adequate information about oral contraceptive pills. The myth that prolonged use of these pills leads to permanent sterility has limited their use in Nigeria, and it may explain why most young females in Nigeria - especially students - prefer abortion to contraception for unwanted pregnancy. ${ }^{6}$ In addition, the protective effects of oral contraceptives are virtually unknown by the majority of Nigeria's female population. ${ }^{38}$ This may explain why the proportion of women who used these drugs was low (eg, $<10 \%$ of teenagers).

Among the health care facility sources, the availability of contraceptive pills is higher at private clinics as compared with government family planning and maternal health clinics or hospitals. ${ }^{5,8-10}$ In addition, more married than single women receive contraceptives from the government-run health facilities, including hospitals. ${ }^{7,31-33}$ This may be the reason that the proportion of unmarried teenagers who used oral contraceptives was so low in this study; these individuals may feel that public or government-run facilities do not provide sufficient privacy or a friendly enough atmosphere. The main reason for this unfriendliness is rooted in the cultural fabric of Nigerian society, where many people still regard family planning services as being within the purview of married couples. ${ }^{6,7,31-33}$ In addition, discussions about sex and contraception with young people are still considered inappropriate in Nigeria, even among health care workers. ${ }^{6,7}$ Therefore, there is a great need in Nigeria to promote youth-friendly reproductive services to encourage sexually active young people to increase their contraceptive use. However, this must begin with the mass education of the adult population to change the cultural norms about sex education during adolescence.
The majority of the clients in this study had been educated to the secondary level. This is significant, because educational level is an important factor that affects contraceptive awareness and use. In addition, the proper use of the pill requires a high level of motivation on the part of the user. This motivation is essential, because the efficacy of the pill depends largely on compliance with the treatment regimen. Most of the users of combined oral contraceptive pills were of low parity. This may be related to the fact that women with high parity have many domestic concerns that may interfere with compliance; many of these women tend to opt for methods that are not client dependent (eg, injectable progesterone-only methods, intrauterine contraceptive devices, implants).

\section{Conclusion}

The use of contraception by women in Nigerian society is low. Only a small percentage of teenage girls use combined oral contraceptive pills, despite their suitability, high efficacy, and numerous health benefits for this population. Therefore, there is a strong need for increased awareness and use of contraceptive pills among sexually active teenage girls in Nigeria.

\section{Disclosure}

The authors report no conflicts of interest in this work.

\section{References}

1. Stacey D. Choosing a birth control method. About.com Contraception. [updated 2012 February 11]. Available from: http://contraception.about. $\mathrm{com} / \mathrm{od} /$ contraceptionoverview/bb/considerations.htm. Accessed May 14, 2012.

2. Glasier A. Contraception. In: Edmonds DK, editor. Dewhurst's Textbook of Obstetrics and Gynaecology for Postgraduates. Malden, MA: Blackwell Publishing, Inc; 2007:299-317.

3. van Vlijmen EF, Brouwer JL, Veeger NJ, Eskes TK, de Graeff PA, van der Meer J. Oral contraceptives and the absolute risk of venous thromboembolism in women with single or multiple thrombophilic defects: results from a retrospective family cohort study. Arch Intern Med. 2007;167(3):282-289.

4. Singh S, Darroch JE, Vlassoff M, Nadeau J. Adding It Up: The benefits of investing in sexual and reproductive health. New York, NY: The Alan Guttmacher Institute; 2003.

5. Carr D, Khan M. The Unfinished Agenda: Meeting the needs for family planning in less developed countries. Washington, DC: Population Reference Bureau; 2004.

6. Otoide VO, Oronsaye F, Okonofua FE. Why Nigerian adolescents seek abortion rather than contraception: evidence from focus-group discussions. Int Fam Plan Perspect. 2001;27(2):77-81.

7. Abiodun OM, Balogun OR. Sexual activity and contraceptive use among young female students of tertiary educational institutions in Ilorin, Nigeria. Contraception. 2009;79:146-149.

8. Federal Republic of Nigeria. National Policy on Population for Development, Unity, Progress and Self-Reliance. Lagos, Nigeria: Department of Population Activities, Federal Ministry of Health; 1988.

9. Adekunle AO. Recent advances in contraceptive and development. In: Friday O, Kunle O, editors. Contemporary Obstetrics and Gynaecology for Developing Countries. Benin City: Women's Health and Action Research Centre; 2003:110-127. 
10. Clerk NT, Ladipo OA. Contraception. In: Agboola A, editor. Textbook of Obstetrics and Gynaecology for Medical Students. Ibadan: Heinemann Educational Books; 2006:145-154.

11. Curtis KM, Chrisman CE, Peterson HB; WHO Programme for Mapping Best Practices in Reproductive Health. Contraception for women in selected circumstances. Obstet Gynecol. 2002;99:1100-1112.

12. Hatcher RA, Trussell J, Stewart F, et al: Contraceptive Technology. 18th ed. New York, NY: Adent Media; 2004:236, 374, 327.

13. Faculty of Family Planning and Reproductive Health Care, Clinical Effectiveness Unit. FFPRHC Guidance (October 2003): first prescription of combined oral contraception. J Fam Plann Reprod Health Care 2003;29:209-222.

14. Gallo MF, Grimes DA, Schulz KF, Helmerhorst FM. Combination estrogen-progestin contraceptives and body weight: systematic review of randomized controlled trials. Obstet Gynecol. 2004;103:359-373.

15. Larsson G, Milsom I, Lindstedt G, Rybo G. The influence of low dose combined oral contraceptive on menstrual period and iron status. Contraception. 1992;46:327-334.

16. Thorogood M, Villard-Mackintosh L. Combined oral contraceptive pill: risks and benefits. Br Med Bull. 1993;49:124-139.

17. Monga A, editor. Fertility control. In: Gynaecology by Ten Teachers, 18th ed. London: Edward Arnold (Publishers) Ltd; 2006:59-70.

18. Holt VL, Cushing-Haugen KL, Daling JR. Oral contraceptives, tubal sterilization, and functional ovarian cyst risk. J Obstet Gynecol. 2003;102:252-258.

19. Hatcher RA, Trussel J, Stewart F, et al. The pill: combined oral contraceptives. Contracept Technol. 1994;18:223-248.

20. Burkman RT. Cardiovascular issues with oral contraceptives: evidencebased medicine. Int J Fertil Womens Med. 2000; 45:166-174.

21. Michelle MD, Roland T, Burkman MD. Contraception and family planning. In: Decherny AH, Laurent N. Current Obstetrics and Gynaecologic Diagnosis and Treatment. New York, NY: Lang Medical Books/ McGraw-Hill Companies, Inc; 2003:631-650.

22. Beral V, Hermon C, Kaay C, Hannaford P, Darby S, Reeves G. Mortality associated with oral contraceptive use: 25 year follow up of cohort of 46000 women from Royal College of General Practitioners oral contraception study. BMJ. 1999;318:96-100.

23. Kulier R, Helmerhorst FM, Maitra N, Gülmezoglu AM. Effectiveness and acceptability of progestogens in combined oral contraceptives - a systematic review. Reprod Health. 2004;1:1.

24. Schaffer JI, Hoffman BL, Cunningham FG, et al, editors. Contraception and sterilization. In: Williams Gynaecology. New York: McGraw-Hill Medical; 2008:105-132.

25. Metson D. Lessons from an audit of unplanned pregnancies. BMJ 1988;297:904-906.
26. Audet MC, Morean M, Koltun WD, et al; ORTHO EVRA/EVRA 004 Study Group. Evaluation of contraceptive efficacy and cycle control of a transdermal contraceptive patch vs an oral contraceptive: a randomized controlled trial. JAMA. 2001;285:2347-2354.

27. Contraceptives and congenital anomalies. ACOG Committee Opinion: Committee on Gynecologic Practice. Number 124-July 1993. Int $J$ Gynaecol Obstet. 1993;42(3):316-317.

28. Milsom I, Sundell G, Andersch B. The influence of different combined oral contraceptives on the prevalence and severity of dysmenorrhea. Contraception. 1990;42:497-506.

29. Breast cancer and hormonal contraceptives: collaborative reanalysis of individual data on 53297 women with breast cancer and 100 239 women without breast cancer from 54 epidemiological studies. Collaborative Group on Hormonal Factors in Breast Cancer. Lancet 1996;347:1717-1727.

30. Hatcher RA, Rinehart W, Blackburn R, et al. Low dose combined oral contraceptives. The essentials of contraceptive technology. 2001;3:5-1-5-25.

31. Oye-Adeniran BA, Adewole IF, Odeyemi KA, Ekanem EE, Umoh AV. Contraceptive prevalence among young women in Nigeria. J Obstet Gynaecol. 2005;25:182-185.

32. Amazigo U, Silva N, Kaufman J, Obikeze DS. Sexual activity and contraceptive knowledge and use among in-school adolescents in Nigeria. Int Fam Plan Perspect. 1997;23:28-33.

33. Okpani AOU, Okpani JU. Sexual activity and contraceptive use among female adolescents--a report from Port Harcourt, Nigeria. Afr J Reprod Health. 2000;4:40-47.

34. Odujinrin OM. Sexual activity, contraceptive practice and abortion among adolescents in Lagos, Nigeria. Int J Gynaecol Obstet. 1991;34:361-366.

35. Makinwa AP. Sexual behaviour. Reproductive knowledge and contraceptive use among urban youths in Nigeria. Int Fam Plan Perspect. 1992;18(2):66-70.

36. National Population Commission (NPC) [Nigeria] and ICF Macro. Nigeria Demographic and Health Survey 2008. Abuja, Nigeria: National Population Commission and ICF Macro; 2009.

37. Okogbenin SA, Okpere EE. Age and reproductive outcome. In: Okpere EE, editor. Clinical Obstetrics, revised edition. Benin City: Uniben Press; 2004:398-400.

38. Women's perceptions of the safety of the pill: a survey in eight developing countries. Report of the perceptions of the pill survey group. J Biosoc Sci.1987;19:313-321.
Open Access Journal of Contraception

\section{Publish your work in this journal}

Open Access Journal of Contraception is an international, peerreviewed, open access, online journal, publishing original research, reports, reviews and commentaries on all areas of contraception. In addition to clinical research, demographics and health-related aspects, the journal welcomes new findings in animal and preclinical studies

\section{Dovepress}

relating to understanding the biological mechanisms and practical development of new contraceptive agents. The manuscript management system is completely online and includes a very quick and fair peer-review system. Visit http://www.dovepress.com/testimonials.php to read real quotes from published authors. 